\title{
Analysis of Neodymium-Doped Yttrium-Aluminum- Garnet Laser and Experimental Prospects for Cutting Micro-Thin Black Walnut Veneers in Industry
}

\author{
Bakary S. Doumbia, ${ }^{\mathrm{a}, \mathrm{b}, \mathrm{c}}$ Chunmei Yang, ${ }^{\mathrm{a}, \mathrm{b}, *}$ Yan Ma, ${ }^{\mathrm{a}}$ Ting Jiang, ${ }^{\mathrm{a}, \mathrm{b}}$ Xiang Li,,${ }^{\mathrm{a}, \mathrm{b}}$ and \\ Wenji Yu ${ }^{\text {b,d,* }}$
}

\begin{abstract}
By structurally and practically analyzing the use of $\mathrm{Nd}$ : YAG laser for cutting black walnut veneer, this study considered practical and environmental concerns regarding the global warming protection measures. A numerical model of laser wood veneer cutting was based on the relation between process parameters and the material thickness. $A$ pulsed Nd: YAG was used to cut black walnut veneer of $0.3 \mathrm{~mm}$ thickness under different machining conditions regarding laser power and cutting speed to study the cut kerf width. An analysis of variance was conducted to test the significance of machining parameters. The parameters studied were laser power, cutting speed, kerf width, cut surface, safety, and ecofriendliness. The results showed that the kerf width decreased significantly with increased cut speed and, inversely, by laser output power. An efficient cut with a narrow kerf, clean and smooth, with less burn, was possible at laser cutting speeds of $2.5,5.0$, and $5.5 \mathrm{~mm} / \mathrm{s}$ with kerf widths of 0.544 , $0.69,0.62 \mathrm{~mm}$, respectively. As multiple factors affect the micro-thin wood laser cutting process, finding the optimal process parameters is crucial for successful machining with no burn effect.
\end{abstract}

Keywords: Black walnut veneer; Cut quality; Eco-friendly; Kerf width; Micro-thin wood objects;

Nanosecond Nd-YAG laser

Contact information: a: Forestry and Woodworking Machinery Engineering Technology Center, Northeast Forestry University, Harbin 150040, China; b: Northeast Forestry University, College of Mechanical and Electrical Engineering, Harbin, 150040, China; c: University of Science Technical and Technology of Bamako (USTTB), Faculty of Sciences and Technology (FAST), Bamako 423, Mali; d: Research Institute of Wood Industry, Chinese Academy of Forestry, Beijing, 100091, China;

*Corresponding authors: yuwenji@caf.ac.cn; ycmnefu@126.com

\section{INTRODUCTION}

Rapid prototyping technologies (RPTs) have been applied in various sectors, including the manufacturing of metallic and non-metal materials, which require lasers. Object laser cutting is one of the most applied techniques with numerous kinds of lasers. The most commonly used, conventional laser techniques are carbon dioxide $\left(\mathrm{CO}_{2}\right)$, fiber/disk, neodymium-doped: yttrium-aluminum-garnet (Nd: YAG), and direct diode lasers (Choudhury and Shirley 2010; Tahir et al. 2012a; Pocorni et al. 2017). Some of these lasers are physically identical but utterly different in terms of physical properties, components, operating modes and processes, and the range of applicability in terms of materials. These lasers and their derivatives have become more competitive regarding the multiple advantages owned and the service quality that they may provide. The selection of laser cutting technique depends on the desired object and on the precision and flexibility of cutting the contour (laser output power and cutting speed), cut edge quality, small heat- 
affected zone (HAZ), and the potential for process automatization (Powell and Kaplan 2004). For efficiency and versatility purposes, a gas or liquid is often used in laser cutting to remove debris from the cut surface.

The Nd: YAG solid-state laser is used for high precision and micro-processing applications. While it is practically suited for metallic materials application, its application with organic materials (nonmetallic) has grown significantly. As a result, a low-power 500 W Nd: YAG laser with $20 \mathrm{~mm} / \mathrm{s}$ of cut speed has been used to cut nylon seat belts (Tahir et al. 2012a). The laser beam cut and sealed the workpiece with a minimum flare without any burr observed on the edges. However, the process freed some noxious gases that are dangerous for user health and environmentally harmful. A $275 \mathrm{~W} \mathrm{Nd:} \mathrm{YAG} \mathrm{laser} \mathrm{of} 254$ $\mathrm{mm}$ of focal length, with a coaxial gas flow, has been used to cleanly cut $114 \mathrm{~mm}$ thick of rubber foam at a laser speed of $16.6 \mathrm{~mm} / \mathrm{s}$ without any sign of burn reported (Tahir et al. 2012a). As reported in Peters and Marshall (1975), a $1 \mathrm{~kW} \mathrm{Nd:} \mathrm{YAG} \mathrm{laser} \mathrm{was} \mathrm{used} \mathrm{to} \mathrm{cut}$ the plastic part. In sum, the Nd: YAG laser is an excellent technique for cutting speed, cleanliness, and overall process time consumption.

In pulsed mode, the laser works in pulses, generating short pulses, each with high laser output power. The pulse duration and pause duration alternate at short intervals and produce pulses with maximum output. The shortest-duration laser created to this point produced pulses of six-femtoseconds duration, a time that corresponds to the only three optical cycles (Fork et al. 1989). The more energetic pulsed mode is suited for materials processing applications (Powell 1998). Low-powered lasers mainly use the process for specific applications, resulting in small contours or embellishment slats with a width smaller than the material thickness. Pulsed lasers are widely applied for material processing, namely, in fine cutting, welding, and hole drilling (Olsen and Alting 1995). They are flexible equipment for scientists and engineers that have achieved a vital function in current optical physics (Zhu and Hall 1997). Notably, the primary pulsed laser was invented by T. H. Maiman (Maiman 1960). Due to their high peak power, pulsed lasers have helped researchers to view and study outcomes that scale nonlinearly with growing the strength of the optical region. These kinds of lasers can be highly cost-effective. They have been shown to be especially useful in studying transient phenomena that occur in periods as brief as femtoseconds or so long as milliseconds or beyond (Zhu and Hall 1997). Accordingly, pulsed lasers have been utilized for a wide range of products and items for decades and have become an indispensable part of advanced manufacturing (AM) technology (Trumpf 2007). As a result, for current use, a pulsed Nd: YAG solid-state laser was used to investigate the cut surface quality of different types of wood materials regarding the impact of the laser energy, feed rate, and kerf depth, showing excellent results depending on the laser pulse frequency, power, and feed rate (Xinbo et al. 2016). Yang et al. (2018) used pulsed Nd: YAG laser with and without water jet-assisted to cut Korean pinewood with a thickness of $2 \mathrm{~mm}$. The study showed significant machining results depending on the influence of the cutting speed, laser power on cut surface quality, namely the kerf of the cut. Yang et al. (2017) proposed the nanosecond laser processing theory of micronized wood fibers, demonstrated the possibility of cutting micronized wood fibers along the grain, and concluded that the use of a nanosecond laser ensures accuracy in the micron range.

Wood is a renewable, biodegradable material with a wide range of applications, from furniture to architecture. Wood veneer is a thin layer of woodcut mainly used for interior decoration applications. It is ideal for residential projects, hotel projects, offices, etc. Moreover, veneer is processed to create various products such as veneer parquet, 
flexible veneer sheets, veneer boards, and veneer wallpaper. In manufacturing sectors, laser applications provide new theories and have made things comfortable and straightforward (Yang et al. 2017). Consequently, the unique beam characterizations of Nd: YAG lasers promote safety and flexibility compared with other lasers. However, in terms of its application for wood veneer parts machining, there is an absence of detailed investigations regarding the laser structure, process analysis, and applicability.

This paper examines Nd: YAG laser cutting of black walnut veneers for use in industry. The findings provide an insight for the structural and practical use of Nd: YAG laser cutting of micro-thin wood objects regarding laser safety and eco-friendness.

\section{Structure and Analysis of Neodymium-Doped: Yttrium-Aluminum-Garnet (Nd: Yag) Laser}

Yttrium aluminum garnet (YAG), a single synthetic crystal of $\mathrm{Y}_{3} \mathrm{Al}_{5} \mathrm{O}_{12}$ doped with a low percentage of the rare-earth element neodymium $\left(\mathrm{Nd}^{3+}\right.$ ion $)$, which constitutes the active laser medium (Nd: YAG laser); it transmits infrared laser radiation at the wavelength of $1.064 \mu \mathrm{m}$. The ion $\mathrm{Nd}^{3+}$ hosts the YAG carrying out the lasing action.

\section{Construction and Principle}

The broadband optical radiation from the pulsed krypton flash, continuous wave (CW) lamp, or laser diode coupled into the crystal excites the active medium $\left(\mathrm{Nd}^{3+}\right.$ ions) to the high energy levels (Wandera 2006). During the passage from the metastable state to the ground state, the laser beam emits a wavelength of is $1.064 \mu \mathrm{m}$. YAG crystal acts as a positive lens when pumped because of the high temperature at the center as the cooling water is in contact only with the outer surface. This thermal lensing of the rod increases while increasing the pump power (Almeida et al. 2018). An elliptical cylindrical reflector keeps the crystal (laser rod) and the flash lamp at its focus. Both ends of the laser rod are polished. It is optically active in the resonator. This optical resonator is constituted of two mirrors $M_{1}$ and $M_{2}$, respectively, highly and partially reflective (Fig. 1). The optical characteristic variation depends on the laser parameters, which will affect the laser output power.

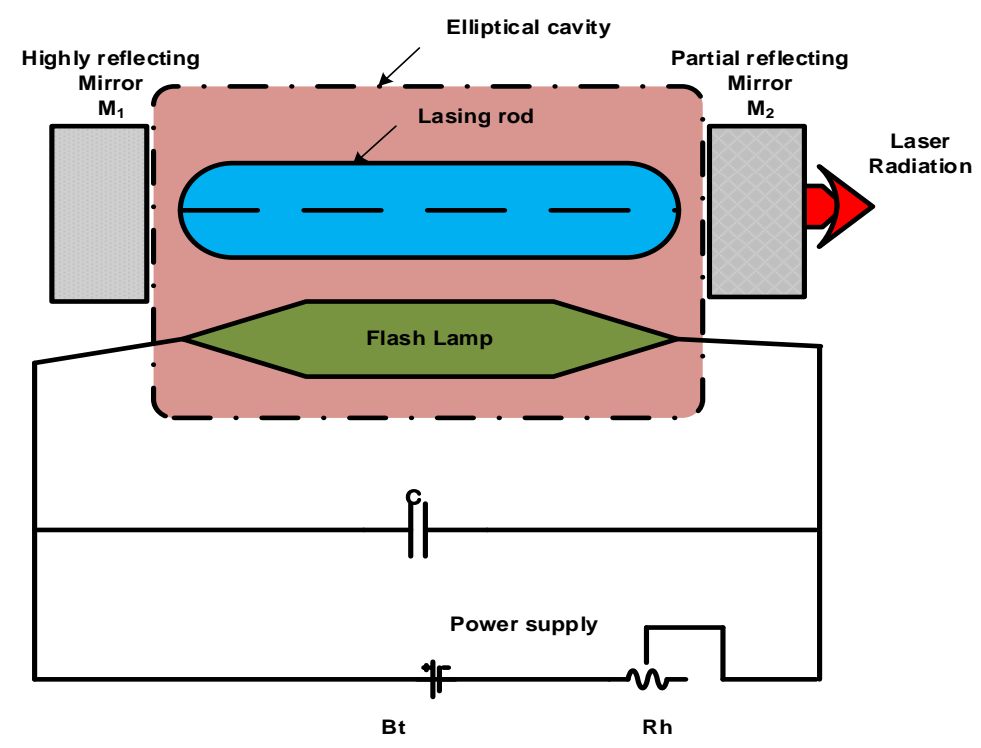

Fig. 1. Solid-state Nd: YAG laser construction mode 
Nd: YAG is a four-level laser. Figure 2 displays the simplified four-level energy diagram of ions neodymium $\left(\mathrm{Nd}^{3+}\right)$. Once the krypton flash lamp is switched on, as shown in Fig. 1, the atoms of $\mathrm{Nd}^{3+}$ are pumped from the ground state energy level $\left(\mathrm{E}_{0}\right)$ to the upper states, $\mathrm{E}_{3}$ and $\mathrm{E}_{4}$, constituting the crucial levels of the pump bands by absorption of the radiation of $0.73 \mu \mathrm{m}$ and $0.80 \mu \mathrm{m}$, respectively, for $\mathrm{E}_{3}$ and $\mathrm{E}_{4}$ (Svelto 2010). Form $\mathrm{E}_{3}$ and $\mathrm{E}_{4}$, atoms of $\mathrm{Nd}^{3+}$ transit to the energy state-level $\mathrm{E}_{2}$ (metastable-state) by the non-radiative transition. The excited $\mathrm{Nd}^{3+}$ ions stay about $230 \mu \mathrm{s}$ in $\mathrm{E}_{2}$, allowing a transition to energy state-level $E_{1}$ (Shabbusharma 2020). During this transition from $E_{2}$ and $E_{1}$, radiation of $1.06 \mu \mathrm{m}$ of wavelength is emitted. This photon $(\lambda=1.06 \mu \mathrm{m})$, while stimulating the transition, oscillates between the two mirrors $\mathrm{M}_{2}$ and $\mathrm{M}_{1}$. Thus, through the partial reflecting mirror $\mathrm{M}_{2}$, a coherent output beam of the laser is obtained, as shown in Fig. 1. The population of ions $\mathrm{Nd}^{3+}$ on $\mathrm{E}_{1}$ state is lower than that on state $\mathrm{E}_{2}$, so the population inversion is achieved (Shabbusharma 2020). The ions $\mathrm{Nd}^{3+}$ in the energy state $\mathrm{E}_{1}$ of (approx. $0.25 \mathrm{eV}$ ) quickly jump to ground state energy level $\mathrm{E}_{0}$ under non-radiative transition (Svelto 2010; Shabbusharma 2020).

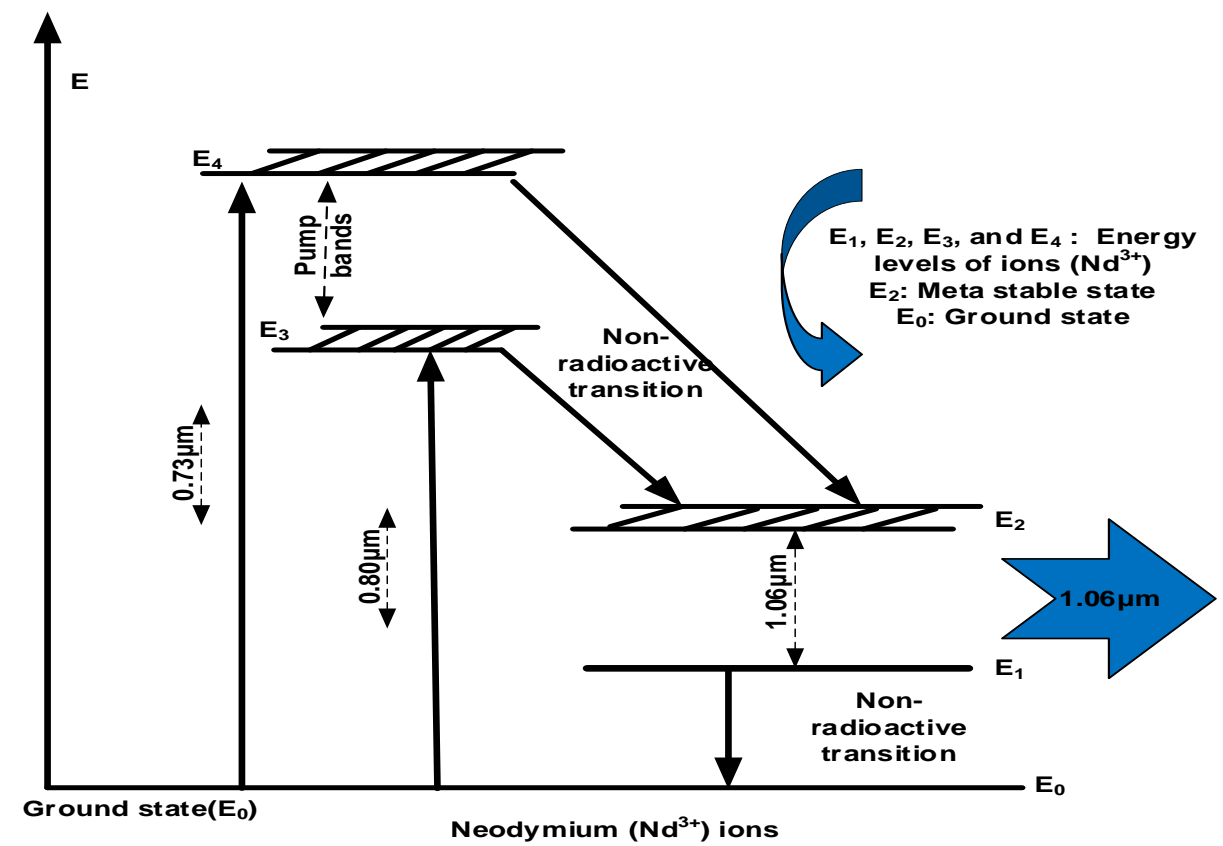

Fig. 2. Simplified energy state diagram and principle of Nd: YAG laser

\section{Operating modes and processes}

In pulsed mode, the flash lamps are explicitly designed for the typical repetitive high-peak-current electrical pulses to create the laser pulses (Borges 2008). The flash lamps have unique design features to improve their reliability and life regarding the high peak currents in the lamp during a pulse (Wandera 2006). Therefore, they can withstand the higher delivered average power. On the other hand, operating in the continuous mode $(\mathrm{CW})$ requires much higher pumping energy because of lower photon flux in the laser. The cooling optimized for the high-power operation, and the high-pressure spikes of pulsing lights source, which is absent with $\mathrm{CW}$ lamps. The lamp jacket walls are thin, and the electrode size increases for better cooling (Wandera 2006). The electrodes are formed for repeatable arc production. Simultaneously, the mass and placement of the conductors are optimized for thermal stresses, whereas the metal electrode seals to the swallowed glass. The Nd: YAG laser operating setup on the object is schematized in Fig. 3. 


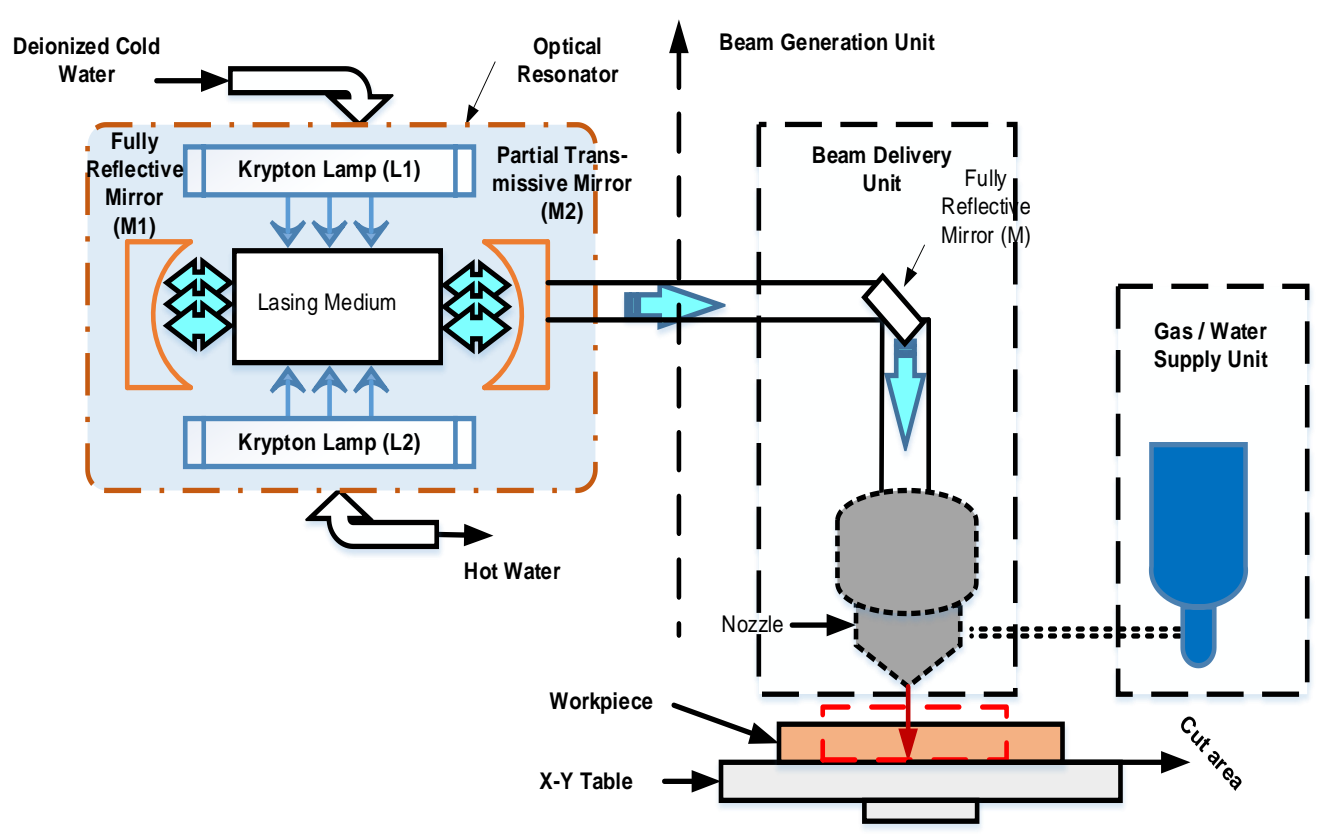

Fig. 3. $\mathrm{Nd}$ : YAG experimental laser setup

\section{Nd: YAG Laser for Industrial Laser Cutting Applications}

In advanced manufacturing (AM), the lasers with high beam quality and high power are more appropriate for cutting applications. Consequently, Nd: YAG laser technology is suited, straightforward, and overwhelmingly used high-power solid-state laser for high precision and micro-processing applications (Schuocker 1989; Guillas et al. 1990; Kalokasidis et al. 2013). However, the laser beam is quantitatively responsible for predicting suited types of materials for applications. This laser is available for application with an output power capability of up to $4,500 \mathrm{~W}$ (Senthilkumar et al. 2016). Nd: YAG lasers emit in the near-infrared at a wavelength of $1.06 \mu \mathrm{m}$. This wavelength is suited for overwhelming types of materials with less restriction. As a result, it is applied to a wide range of materials, including metallic and nonmetallic (Leone et al. 2009; Tahir et al. 2012a; Sharma and Yadava 2013; Gautam and Pandey 2018; Sharma and Yadava 2018). The YAG laser equipment is suited for machining complex geometries in general and, in particular, reflective items (Sharma and Yadava 2018). YAG is one of the sought-after laser machines for applications in sophisticated fields and susceptible objects.

\section{For cutting nonmetallic objects}

In terms of cutting items, Nd: YAG laser processes differently with different kinds of materials. Notably, most organic materials faintly absorb the YAG laser beam. However, it is practically efficient for operating with a certain number of nonmetallic materials, namely plastics, wood, rubber, and acrylic. Consequently, the use of $\mathrm{Nd}$ : YAG laser for cutting plastics and wooden items have recently gradually increased. As a result, numerous investigations have been reported using low-powered $\mathrm{Nd}$ : YAG lasers to cutting nonmetallic materials. A $1 \mathrm{~kW} \mathrm{Nd:} \mathrm{YAG} \mathrm{laser} \mathrm{was} \mathrm{used} \mathrm{to} \mathrm{cut} \mathrm{reinforced} \mathrm{plastic} \mathrm{with} \mathrm{the}$ mold parts and compared with other techniques, such as water jet cutting, milling, punching, cutting traditional knife, and hot ultrasonic blade (Gong 2014). The study shows that the Nd: YAG laser cutting is faster and cleaner, and with a minimum time of process 
than other techniques. A $560 \mathrm{~W}$ Nd: YAG laser was used to remove the ceramic material at a rate of $5.3 \mathrm{~mm}^{3} / \mathrm{s}$ (Sharma and Yadava 2018). A pulsed Nd: YAG solid-state laser was used to investigate the cutting quality of different types of wood sheets regarding the impact of the laser energy, feed rate, and kerf depth (Xinbo et al. 2016). The study found excellent results depending on the laser pulse frequency, power, and feed rate. Yang et al. (2018) used a pulsed Nd: YAG laser with and without water jet-assisted to cut Korean pinewood (Pinus koraiensis) with a thickness of $2 \mathrm{~mm}$. In terms of the cut kerf, the study shows the increase with the increase of laser power and then the decrease with the increase of laser cutting speed.

\section{EXPERIMENTAL}

\section{Materials and Equipment}

This study analyzed the use of Nd: YAG laser laminated object manufacturing (LOM) based technology for micro-thin wood products prototyping in the industry. The system contained a solid-state laser, (Nd: YAG) laser, JDW3-250 laser power supply (Beijing, China). The Nd: YAG laser had a focal length of $15 \mathrm{~cm}$ and a spot diameter of 1 $\mathrm{mm}$. The overall equipment is a mounting system with a calibration platform (Fig. 4(c)). A commercial black walnut veneer of $0.3 \mathrm{~mm}$ thick with $10 \%$ moisture content was used as the proceeded material. This workpiece was clamped on the lifting platform, as shown in Fig. 4(b). The system was cooled at $600 \mathrm{~W}$ by a PH-LW06-BLP laser cooling system (Shenzhen, China).

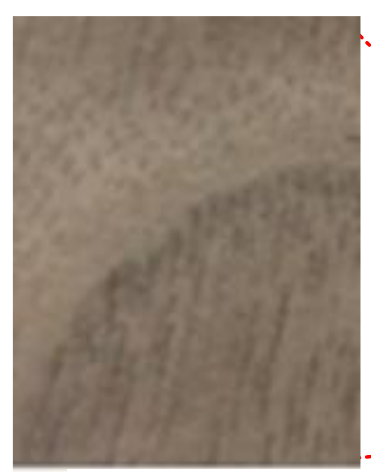

(a)

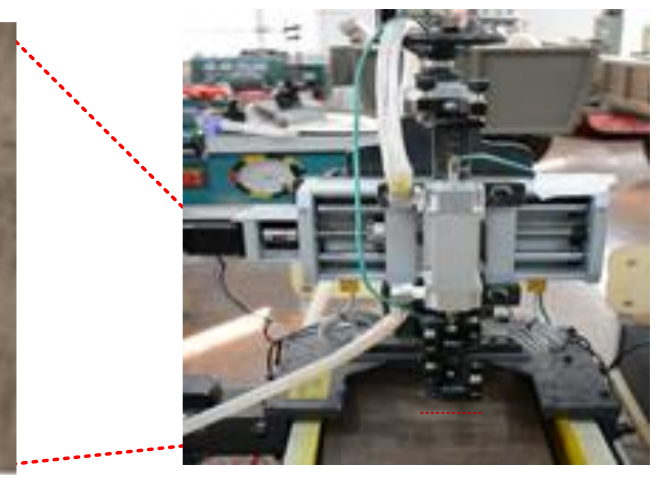

(b)

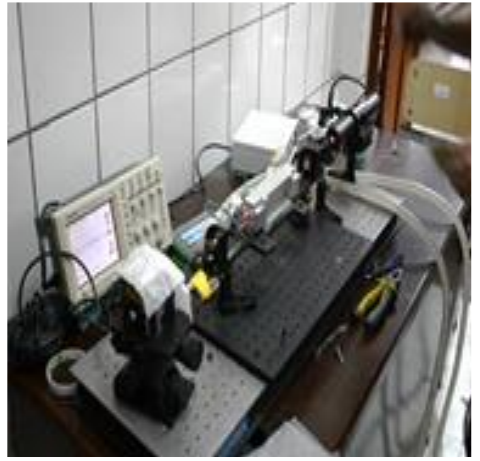

(c)

Fig. 4. Material and equipment for pulsed Nd: YAG laser experimental test. (a) Black walnut, (b) Nd: YAG laser system, (c) Laser calibration.

\section{Process Methods}

The nanosecond Nd: YAG was tested for cutting black walnut veneer through numerical and experimental analyses regarding parameters affecting the efficient machining with minimum burning effect. The veneer workpiece was laser cut at different cutting speeds corresponding to a laser output power. The cut surface quality and geometry related to the kerf width was investigated through measurement and microscopic observation. An analysis of variance was conducted to elucidate the relation between the laser cutting speed and the kerf width at specific laser output power. The average laser power and cutting speed were independent variables. The dependent variable under 
investigation was the kerf width; additionally, non-numerical factors such as laser safety and eco-friendliness were considered.

\section{Experimental process}

A pre-experiment was conducted to calibrate the laser. An atomic gas type laser (helium-neon; He-Ne) with a focal length of $15 \mathrm{~cm}$ was used for laser calibration, as shown in Fig. 4(c). The measured focal length was $15.3 \mathrm{~cm}$ after calibration. The cut head of the Nd: YAG laser was mounted with the equipment by adjusting the working table for a chosen distance. Regarding the cut geometry, a plan interpolation allowed full movement along the workpiece at a planned position. Considering the black walnut veneer fiber structure, and additionally for an accurate, straightforward, and efficient cut results in terms of kerf width, a linear vertical laser-cut of the wood veneer was adopted. Table 1 depicts the laser parameters and characteristics. The black walnut laser-cut was performed according to two machining conditions related to laser output power and cutting speed. The cut area was blown using compressed air flow (see Fig. 4(b)). An optical microscope was used for visualizing, calculating the kerf width, and for cut surface micrographic analysis.

Table 1. Nd: YAG Laser Parameters

\begin{tabular}{|c|c|c|c|}
\hline Pulse Width $(\mu \mathrm{s})$ & Pulse Frequency $(\mathrm{Hz})$ & Pulse Voltage $(\mathrm{V})$ & Pulse Energy $(\mathrm{m} . \mathrm{J})$ \\
\hline 200 & 1 & 300 to 800 & 10.8 to 489 \\
\hline 200 & 5 & 300 to 800 & 16.4 to 578 \\
\hline 200 & 10 & 300 to 800 & 18.4 to 602 \\
\hline
\end{tabular}

\section{Numerical process}

During Nd: YAG micro-thin wood laser cutting process, as schematized in Fig. 3, numerous parameters were considered in terms of cutting quality, including the type of wood material, texture, thickness, water content, laser output power, cutting speed, etc. Due to the invariance of black walnut veneer thickness and its water content, the influence of laser power and cutting speed on cutting quality, namely the cut kerf, were studied. Depending on the laser power density, the cut can be efficient or not producing irradiation to cut through the workpiece. Thus, if the laser power density of the irradiation is enough, the material thermal decomposition is rapid, resulting in less heat transfer on the outside of the cutting area. Consequently, the cutting surface is slightly dark but presenting remarkable cutting quality. However, if the laser power density of laser radiation is insufficient, the workpiece may not cut thoroughly, and the material ignition point is reached, provoking slag and burning, which leads to a carbonized cut surface with a sizeable cut geometry.

\section{Equations}

As reported previously (Zhou and Mahdavian 2004; Xie et al. 2008), the mathematical model of Nd: YAG micro-thin wood laser cutting can be deduced as follows. During the process, the laser beam is focused on the surface of the workpiece with a radius of $R$. The cut depth occurs at the center $1 / e^{2}$ of the focused radius, as shown in Fig. 5. Because the cut depth fall to the center $1 / e^{2}$ of the focused radius, so the energy source distributed along the central line of the laser beam-moving trajectory is solely considered. Therefore, Eq. 1 expresses the balanced equation of energy conservation.

$$
E_{i}=E_{V}+E_{\text {Loss }}
$$


where $E_{i}$ is the laser input energy $(\mathrm{kJ}), E_{V}$ is the energy required to cut the black walnut part $(\mathrm{kJ}), E_{\text {Loss }}$ is the energy loss $(\mathrm{kJ})$, which has been ignored in this study.

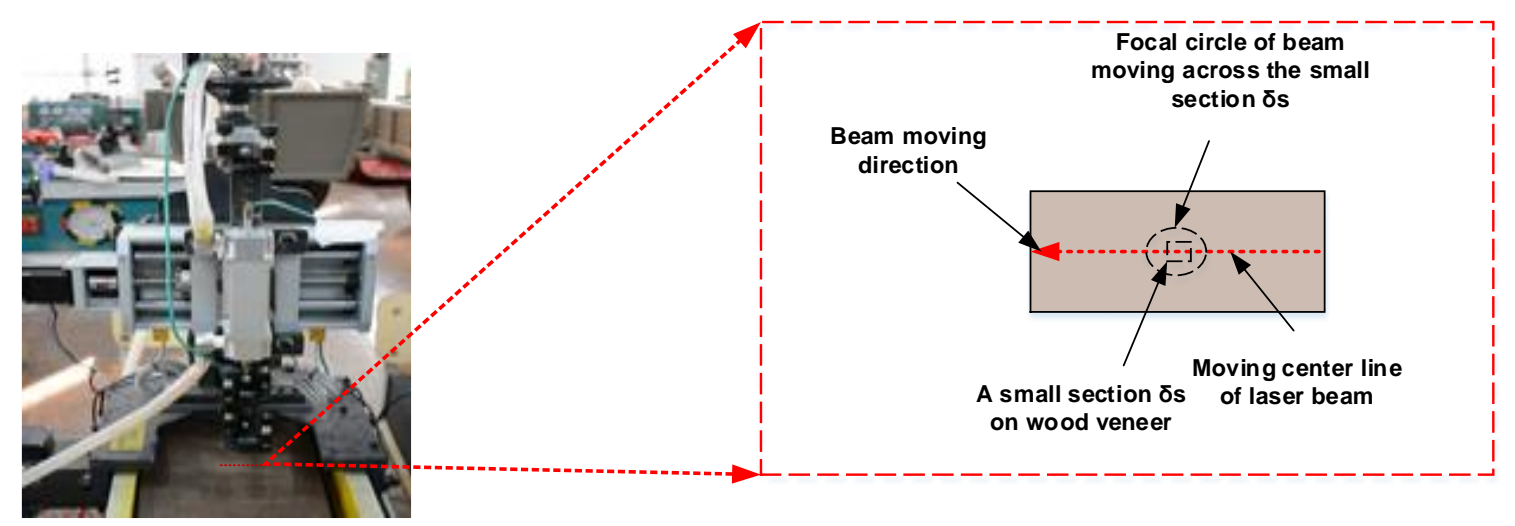

Fig. 5. Laser beam focal point on black walnut veneer.

Considering transverse electromagnetic mode (TEM00), which is suited and used by most industrial laser cutting processes (Zhou and Mahdavian 2004), Eq. 2 expresses the laser intensity distribution following TEM00,

$$
I=\frac{A P_{L}}{\pi R^{2}} \exp \left(-\frac{X^{2}+Y^{2}}{R^{2}}\right)
$$

where $A$ is the laser absorption rate of the material (absorptivity); $P_{L}$ is the laser peak power. $R$ is the laser beam radius, denoting the center's distance to the point where the laser intensity value falls to $1 / e^{2}$.

For pulsed Nd: YAG cutting of black walnut, the cut depth $D(\mathrm{~mm})$ for a small section $\delta S=\delta X . \delta Y$ in the workpiece is expressed by Eq. 3 (Zhou and Mahdavian 2004; Yang et al. 2019),

$$
D=\frac{A}{Q R \sqrt{\pi}} \times \frac{P_{L}}{\vartheta}
$$

where $Q=\rho\left[C_{p}\left(T_{m}-T_{a}\right)+L_{V}\right]$, which is related to the workpiece material. The variable $\rho$ is the material density $\left(\mathrm{kg} / \mathrm{m}^{3}\right), C_{p}$ is the specific heat capacity $\left(\mathrm{J} /\left(\mathrm{kg} .{ }^{\circ} \mathrm{C}\right)\right), T_{m}$ is the melting temperature $\left({ }^{\circ} \mathrm{C}\right), T_{a}$ is the ambient temperature $\left({ }^{\circ} \mathrm{C}\right)$, and $L_{V}$ is the latent heat of vaporization $(\mathrm{J} / \mathrm{kg})$, and $\vartheta$ is the laser cutting speed $(\mathrm{mm} / \mathrm{s})$.

The laser cutting speed $\vartheta$ and power $P_{L}$, and the material properties mainly affect the laser-cut depth. Consequently, the cut depth $D$ is proportional to the laser power and inversely proportional to the laser cutting speed. Because $P_{L}$ and $\vartheta$ are selected to cut through the micro-thin wood workpiece, the cut depth $D$ can be assimilated to the thickness of the black walnut veneer (Yang et al. 2019).

\section{RESULTS AND DISCUSSION}

\section{Results}

Measurements

Considering the thickness of the black walnut of $\mathrm{D}(0.3 \mathrm{~mm})$, as expressed in Eq.3, Table 2 depicts the characteristics of the black walnut veneer material. 
Table 2. Properties and Values of Black Walnut Veneer

\begin{tabular}{|c|c|}
\hline Properties & Value \& Unit \\
\hline Heat capacity $\left(C_{\mathrm{p}}\right)$ & $1.72 .10^{3} \mathrm{~J} /\left(\mathrm{kg} .{ }^{\circ} \mathrm{C}\right)$. \\
\hline Average density $(\rho)$ & $640 \mathrm{~kg} / \mathrm{m}^{3}$. \\
\hline Melting temperature $\left(T_{\mathrm{m}}\right)$ & $500{ }^{\circ} \mathrm{C}$ \\
\hline Latent heat of vaporization $(L v)$ & $300.10^{3} \mathrm{~J} / \mathrm{kg}$ \\
\hline
\end{tabular}

The laser pulse width and focal radius are respectively $(t=200 \mu \mathrm{s}, R=0.5 \mathrm{~mm})$, with an absorptivity $(A=0.5)$. The ambient temperature $\left(T_{\mathrm{a}}\right)$ was selected as $25{ }^{\circ} \mathrm{C}$. Therefore, through calculation, $Q=7.149 .10^{8} \mathrm{~J}$. Therefore, from Eq. 3, Eq. 4 deduces laser cutting as a function of peak power,

$$
\vartheta=\frac{P_{L}}{380.1}
$$

where $P_{L}(\mathrm{~W})$ denotes the average laser power, which is a function of laser single-pulse energy $E(\mathrm{~J})$ and the pulse frequency $f(\mathrm{~Hz})$ expressed by Eq. 5 .

$$
P_{L}=E \times f
$$

As a result, Table 3 reports the numerical values of the cutting speed function of laser power. The discharge voltage had a noticeable impact on laser pulse energy and cutting speed. Consequently, the increase of laser discharge voltage resulted in higher average power, increasing laser cutting speed at a constant pulse frequency.

Table 3. Numerical Values of Laser Cutting Speed (Yang et al. 2019)

\begin{tabular}{|c|c|c|c|}
\hline $\begin{array}{c}\text { Discharge Voltage } \\
(\mathrm{V})\end{array}$ & $\begin{array}{c}\text { Single-pulse energy } \\
(\mathrm{m} . \mathrm{J})\end{array}$ & $\begin{array}{c}\text { Pulse Frequency } \\
(\mathrm{Hz})\end{array}$ & $\begin{array}{c}\text { The Cutting Speed } \\
(\mathrm{mm} / \mathrm{s})\end{array}$ \\
\hline 300 & 18.4 & 10 & 0.484 \\
\hline 400 & 96.5 & 10 & 2.538 \\
\hline 500 & 198.2 & 10 & 5.214 \\
\hline 600 & 317.4 & 10 & 8.35 \\
\hline 700 & 468.8 & 10 & 12.334 \\
\hline 800 & 602.3 & 10 & 15.846 \\
\hline
\end{tabular}

Figure 6 depicts the variation between the three variables pulse voltage (V), pulse energy $(\mathrm{m} . \mathrm{J})$, and laser cutting speed $(\mathrm{mm} / \mathrm{s})$.

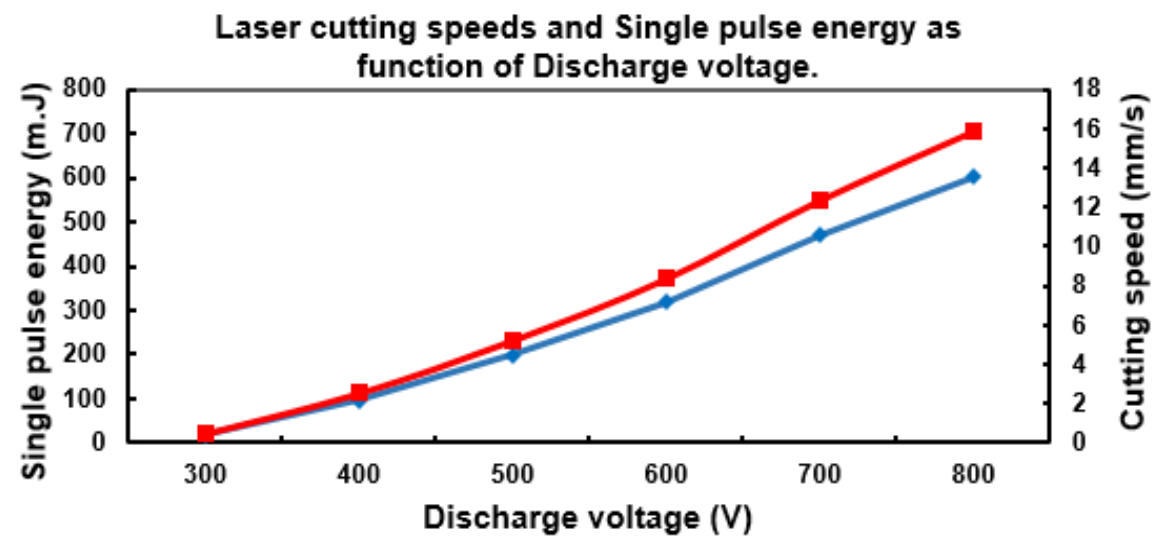

$\longrightarrow$ Single pulse energy (m.J) $\quad \longrightarrow$ Cutting speed $(\mathrm{mm} / \mathrm{s})$.

Fig. 6. Laser cutting speed and the pulse energy variation according to the discharge voltage 


\section{Experimental}

Regarding the data in Table 3, two machining conditions were established randomly to carry out the black walnut veneer Nd: YAG laser-cutting test. These two conditions, $S_{1}$ and $S_{2}$, are shown in Table 4.

Table 4. Black Walnut Veneer Laser Cutting Conditions

\begin{tabular}{|c|c|c|c|c|}
\hline $\begin{array}{c}\text { Test } \\
\text { condition }\end{array}$ & $\begin{array}{c}\text { Pulse Voltage } \\
(\mathrm{V})\end{array}$ & $\begin{array}{c}\text { Pulse Energy } \\
(\mathrm{m} . \mathrm{J})\end{array}$ & $\begin{array}{c}\text { Pulse Frequency } \\
(\mathrm{Hz})\end{array}$ & $\begin{array}{c}\text { Cutting Speed } \\
(\mathrm{mm} / \mathrm{s})\end{array}$ \\
\hline $\mathrm{S}_{1}$ & 400 & 96.5 & 10 & $3.0,2.5,2.0,1.5,1.0,0.5$ \\
\hline $\mathrm{S}_{2}$ & 500 & 198.2 & 10 & $5.5,5.0,4.5,4.0,3.5,3.0$ \\
\hline
\end{tabular}

As a result, Figs. 7 and 8 depict the cut surface at different laser cutting speeds under $S_{1}$ and $S_{2}$. Figure 7 shows cut under condition $S_{1}$ at different cutting speeds, namely of $0.5 \mathrm{~mm} / \mathrm{s}, 1.0 \mathrm{~mm} / \mathrm{s}, 1.5 \mathrm{~mm} / \mathrm{s}, 2.0 \mathrm{~mm} / \mathrm{s}, 2.5 \mathrm{~mm} / \mathrm{s}$, and $3.0 \mathrm{~mm} /$. Figure 8 illustrates the result under condition $S_{2}$ with corresponding laser cutting speed of $3.0 \mathrm{~mm} / \mathrm{s}, 3.5 \mathrm{~mm} / \mathrm{s}$, $4.0 \mathrm{~mm} / \mathrm{s}, 4.5 \mathrm{~mm} / \mathrm{s}, 5.0 \mathrm{~mm} / \mathrm{s}$, and $5.5 \mathrm{~mm} / \mathrm{s}$ (Yang et al. 2019).
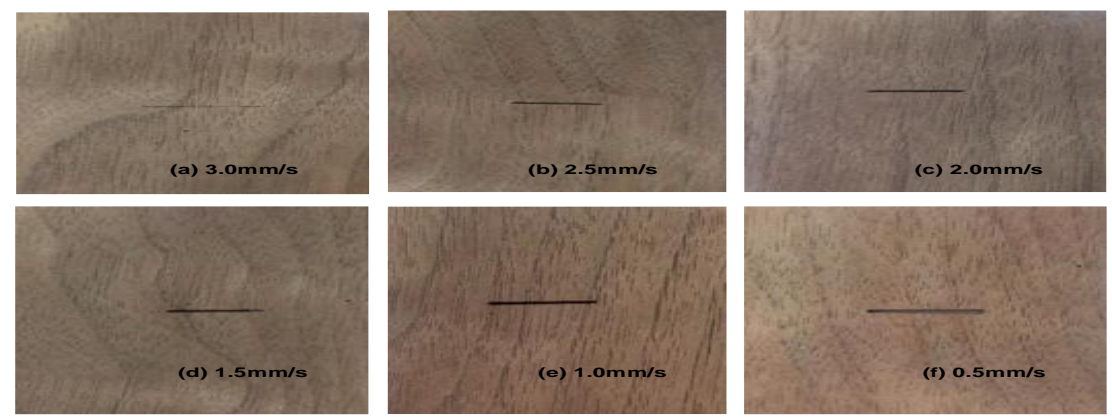

Fig. 7. Black walnut veneer cut surfaces at different laser cutting speeds under the machining condition of $\mathrm{S}_{1}$
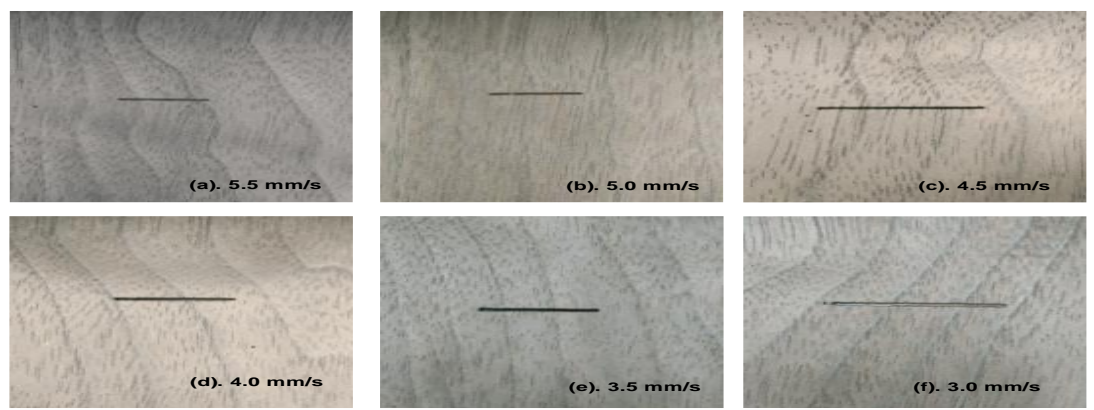

Fig. 8. Black walnut veneer cut surfaces at different laser cutting speeds under the machining condition of $\mathrm{S}_{2}$

Considering the laser cutting speed under different machining conditions $\mathrm{S}_{1}$ and $\mathrm{S}_{2}$ as depicted in Table 4, and for each selected value, five (05) repetitive measurements of the kerf width along the cut line were reported. For each five-measurement group at corresponding laser cutting speed, the kerf width's average value is considered. The data are reported in Table 5 and 6 for $S_{1}$ and $S_{2}$, respectively. For $S_{1}$, the kerf width at the laser cutting speed of $3 \mathrm{~mm} / \mathrm{s}$ was not considered for further analysis. 
Table 5. Kerf Width of the Black Walnut under $S_{1}$

\begin{tabular}{|c|c|}
\hline Laser Cutting Speed $(\mathrm{mm} / \mathrm{s})$ & Kerf Width $(\mathrm{mm})$ \\
\hline 0.5 & 1.209 \\
\hline 1 & 0.908 \\
\hline 1.5 & 0.850 \\
\hline 2 & 0.653 \\
\hline 2.5 & 0.544 \\
\hline
\end{tabular}

Table 6. Kerf Width of the Black Walnut veneer under $\mathrm{S}_{2}$

\begin{tabular}{|c|c|}
\hline Cutting Speed (mm/s) & Kerf Width $(\mathrm{mm})$ \\
\hline 3.0 & 1.35 \\
\hline 3.5 & 1.16 \\
\hline 4.0 & 1.01 \\
\hline 4.5 & 0.78 \\
\hline 5.0 & 0.69 \\
\hline 5.5 & 0.62 \\
\hline
\end{tabular}

Figure 9 shows the graph of the black walnut veneer kerf width as a function of laser cutting speed. Similarly, as reported in Table 6, the relationship between the black walnut veneer kerf width and laser cutting speed under $\mathrm{S}_{2}$ is shown in Fig. 10.

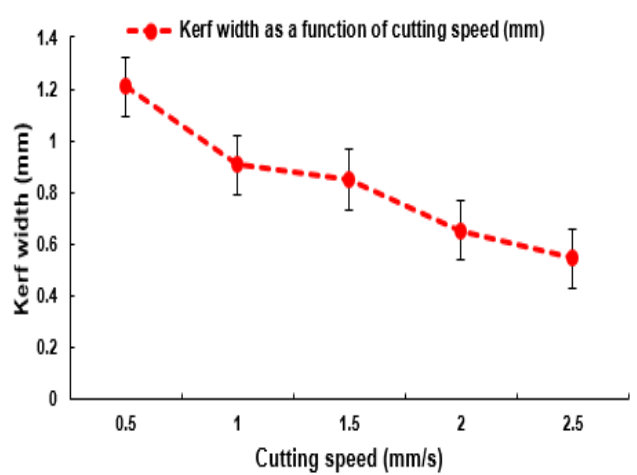

(a)

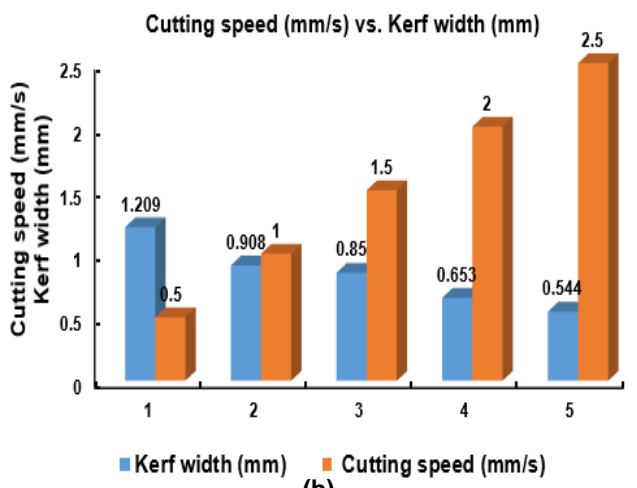

(b)

Fig. 9. The relation between laser cutting speed and the kerf width under $S_{1}$. (a) Kerf width as a function of Cutting speed, (b) Histogram of the Cutting speed vs. Kerf width

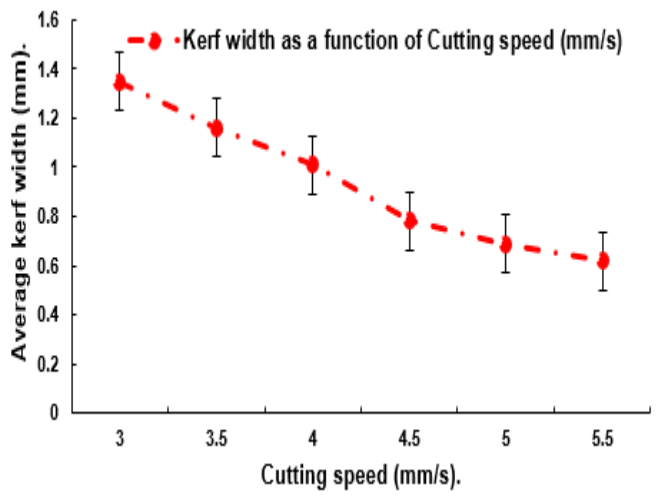

(a)

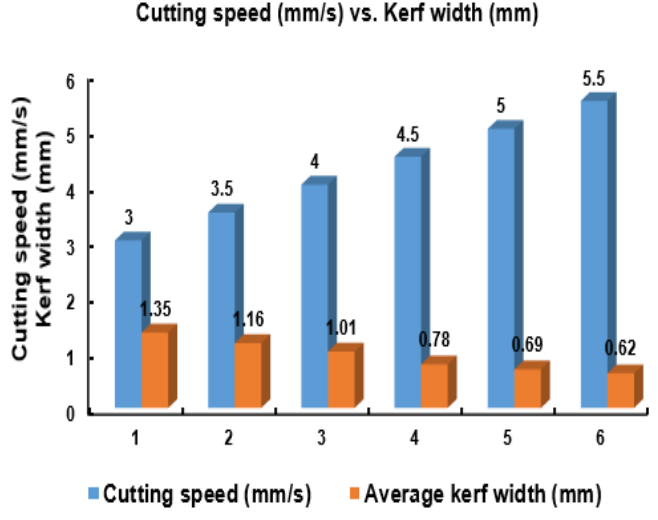

(b)

Fig. 10. The relation between laser cutting speed and the kerf width under $S_{2}$. (a) Kerf width as a function of laser cutting speed, (b) Histogram of the cutting speed vs. Kerf width 


\section{Discussion}

Figures 9 and 10 show a noticeable influence of the laser cutting speed on the kerf width. Indeed, from both conditions $\left(S_{1}\right)$ and $\left(S_{2}\right)$, the kerf width decreased with the increase of the laser cutting speed and vice-versa. Moreover, considering $\mathrm{S}_{1}$ and $\mathrm{S}_{2}$, Oneway ANOVA single factor of laser cutting speed related to the kerf width data is reported in Table 7 and 8 for $S_{1}$ and $S_{2}$, respectively.

Table 7. ANOVA of Kerf Width under $\mathrm{S}_{1}$

\begin{tabular}{|c|c|c|c|c|c|c|}
\hline Source of Variation & SS & df & MS & F & P-value & F crit \\
\hline Between Groups & 1.317398 & 4 & 0.329349 & 101.7453 & $5.35 \mathrm{E}-13$ & 2.866081 \\
\hline Within Groups & 0.06474 & 20 & 0.003237 & & & \\
\hline Total & 1.382138 & 24 & & & & \\
\hline
\end{tabular}

Table 8. ANOVA of Kerf Width under $\mathrm{S}_{2}$

\begin{tabular}{|c|c|c|c|c|c|c|}
\hline Source of Variation & SS & df & MS & F & P-value & F crit \\
\hline Between Groups & 2.033387 & 5 & 0.406677 & 87.55163 & $1.31 \mathrm{E}-14$ & 2.620654 \\
\hline Within Groups & 0.11148 & 24 & 0.004645 & & & \\
\hline Total & 2.144867 & 29 & & & & \\
\hline
\end{tabular}

In Table 7 , considering the machining condition $\left(S_{1}\right)$, in terms of the difference between the kerf widths group at different laser cutting speeds, the P-value (5.35E-13) was much below $\alpha$ (0.05). Besides, the $F$ (101.7453) was much greater than the F-critical (2.8660814). Likewise, considering the condition $\left(\mathrm{S}_{2}\right)$, in Table 8, the P-value (1.31E-14) was far below $\alpha$ (0.05); also, the F (87.5516) was far greater than the F-critical (2.620654).

For both conditions $S_{1}$ and $S_{2}$, there was a significant difference between the kerf widths at different laser cutting speeds under constant output power. In other words, the black walnut veneer laser cutting speed significantly influenced the cut kerf width.

Micro-morphology of black walnut veneer cut surface

Considering the laser cutting speed under machining conditions as reported in Table 4 , while using an optical microscope, the black walnut cut surfaces were visualized. Figure 11 shows the micrograph of the cut surface of the black walnut veneer workpiece at different optimal laser cutting speed underneath $S_{1}$ and $S_{2}$, respectively.

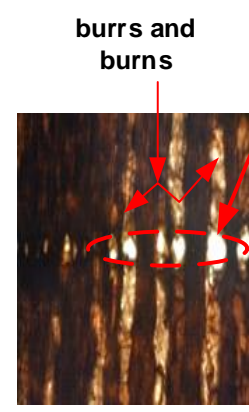

(a) $3.0 \mathrm{~mm} / \mathrm{s}$

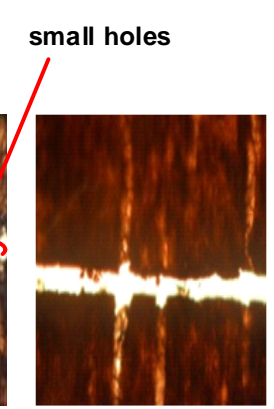

(b) $2.5 \mathrm{~mm} / \mathrm{s}$

(i)

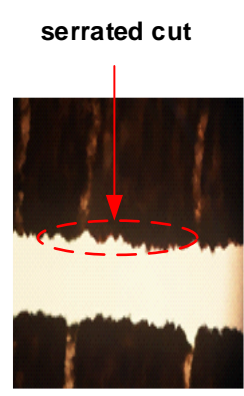

(c) $1.0 \mathrm{~mm} / \mathrm{s}$

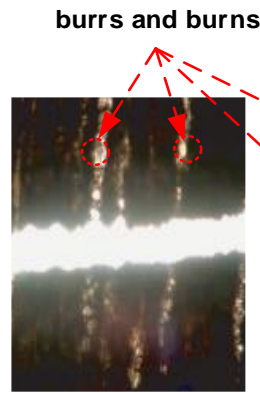

(d) $5.5 \mathrm{~mm} / \mathrm{s}$

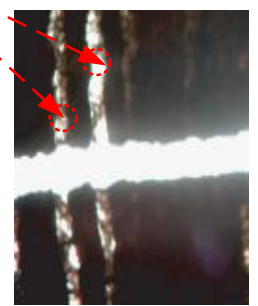

(e) $5.0 \mathrm{~mm} / \mathrm{s}$

(ii)

Fig. 11. Micrograph of the cut surface at different laser cutting speeds. (i) Laser output power condition of $400 \mathrm{~V}$ of pulse voltage, single pulse energy of $96.5 \mathrm{~mJ}$, pulse frequency of $10 \mathrm{~Hz}\left(\mathrm{~S}_{1}\right)$; (ii) Laser output power condition of $500 \mathrm{~V}$ of pulse voltage, single pulse energy of $198.2 \mathrm{~mJ}$, pulse frequency of $10 \mathrm{~Hz}\left(\mathrm{~S}_{2}\right)$. 
Figure 11(i) presents the micrograph of the walnut veneer cut surface under the condition $\mathrm{S}_{1}$ at three different laser cutting speeds, namely $3.0 \mathrm{~mm} / \mathrm{s}, 2.5 \mathrm{~mm} / \mathrm{s}$, and 1.0 $\mathrm{mm} / \mathrm{s}$, respectively for (a), (b), and (c). Figure 11(ii) corresponds to condition $\mathrm{S}_{2}$ at laser cutting speed of $5.5 \mathrm{~mm} / \mathrm{s}$ and $5.0 \mathrm{~mm} / \mathrm{s}$, respectively, for (d) and (e).

As shown in Fig. 11, the kerf width increased with the decreased laser cutting speed and vice-versa at selected laser power in both $\mathrm{S}_{1}$ and $\mathrm{S}_{2}$. In Fig. 11(i).(a), when selecting the cutting speed of $3.0 \mathrm{~mm} / \mathrm{s}$, the laser failed to cut properly through the black walnut veneer while making a series of holes on its surface with noticeable burrs solely and burn effects. This may be due to the fast-cut speed considering the laser pulse energy, causing the black walnut veneer dark surface. In Fig. 11(i).(b), at laser cutting of $2.5 \mathrm{~mm} / \mathrm{s}$, the kerf width of $0.5438 \mathrm{~mm}$ was comparatively small, giving a cut geometry relatively smooth, clean with minimal burns, and less carbonization on the black walnut veneer surface. Comparatively, for the laser cutting speed of $1.0 \mathrm{~mm} / \mathrm{s}$ in Fig.11(i).(c), the kerf width of $0.9084 \mathrm{~mm}$ is about twice that of $2.5 \mathrm{~mm} / \mathrm{s}$ in Fig. 11(i).(b), providing serrated cut geometry with a continuous dark spot covering the surface. In Fig. 11(ii).(d), (e), respectively, for laser cutting speed of $5.5 \mathrm{~mm} / \mathrm{s}$ and $5.0 \mathrm{~mm} / \mathrm{s}$, there is a slight variation on the kerf width, namely $0.622 \mathrm{~mm}$ and $0.688 \mathrm{~mm}$, resulting in smooth cut areas but with noticeable burrs and burn effects, carbonized with continuous dark on veneer surfaces.

The optimal laser cutting speeds with remarkable cut results in terms of cut kerf width, namely $2.5 \mathrm{~mm} / \mathrm{s}, 5.0$, and $5.5 \mathrm{~mm} / \mathrm{s}$ respectively for $S_{1}$ and $S_{2}$, were numerically predicted, as shown in Table 3. Indeed, in Table 3, for condition $\mathrm{S}_{1}$ the laser cutting speed is $2.538 \mathrm{~mm} / \mathrm{s}$. For condition $\mathrm{S}_{2}, 5.214 \mathrm{~mm} / \mathrm{s}$ is noticeable, approximately the average value of $5.5 \mathrm{~mm} / \mathrm{s}$ and $5.0 \mathrm{~mm} / \mathrm{s}$, as shown in Fig. 11 .

Accordingly, for a selected set up with the right parameter combinations, the $\mathrm{Nd}$ : YAG laser can perform to a smaller thermal load, narrow kerf width, and small HAZ (Gong 2014). Because the HAZ and the kerf width depend on the pulse energy, the use of high pulse energy at a short time leads to a decrease of the HAZ and the kerf width (Chien and Gupta 2005). Consequently, pulsed Nd: YAG was efficiently used to cut the CFRP plate of $1 \mathrm{~mm}$ of thickness at a laser cutting speed of about $11 \mathrm{~mm} / \mathrm{s}$ (Leone et al. 2009). The Nd: YAG laser focus on a smaller spot diameter with higher power density leads to efficient machinability in terms of smaller kerf width and less thermal distortion; in other words, the heat-affected zone (HAZ).

\section{Safety and eco-friendliness of Nd: YAG laser}

The Nd: YAG laser for cutting black walnut veneer in particular, and in general for micro-thin wood applications, is a versatile technique. The YAG solid-state laser, like Yb fiber laser, is safe and compact than gas-made lasers (Olsen and Alting 1995; Powell 1998; Hernandez et al. 2007; Hernandez-Castaneda et al. 2009; Hernandez-Castaneda et al. 2011a; Hernandez-Castaneda et al. 2011b). Besides, structurally and practically, there is no need to use noxious gases, and the machining process does not release toxic gases dangerous to users nor ecologically harmful. Pulsed Nd: YAG laser is eco-friendly suited for cutting the black walnut veneer. Additionally, the Nd: YAG laser processes faster, cleaner, with less emission of hazardous smokes (Tahir et al. 2012a; Sharma and Yadava 2018). The Q-switching Nd: YAG laser has higher peak power leading to a clean, smooth cut due to its remarkable vaporization temperature (Kalokasidis et al. 2013).

The present study was limited in terms of process free of burrs and burning effect due to thermal deformation causing carbonization of black walnut veneer cut surfacethese issues due to the complexity of the process parameters. For correction purposes and 
efficient applicability, the right selection of nozzle and the energy carriage can lead to remarkable laser machining results. For micro-thin wood applications, Nd: YAG laser energy carried via an optical fiber wire can be gas-assisted (Tahir et al. 2012b; Li Jinzhe 2016; Jiang et al. 2016) or water-jet assisted (Yang et al. 2018), which provide excellent results, safety, and flexibility in the work environment. The use of Nd: YAG lasers is not solely eco-friendly but also guarantees the user's safety.

Further research related to the present study includes comparative and parametrical analyses of gas or water-assisted YAG laser cutting of micro-thin wood (veneers).

\section{CONCLUSIONS}

1. This study beneficially uses numerical methods to define and predict influenced parameters in cutting kerf width of black walnut veneer. In terms of cut surface quality, the laser cutting speed and output power show significant effects. For a selected laser output power condition, the kerf width increases while the laser cutting speed decreases and inversely.

2. Pulsed low powered Nd: YAG laser cut the black walnut veneer of $0.3 \mathrm{~mm}$ of thickness with minimum material thermal deformation, no significant burning effect, and a fast process with fewer restrictions.

3. Nd: YAG is a versatile laser suitable for cutting black walnut wood veneer, leading to a clean-cut result, smooth surface with narrow cut kerf. Plus, there is no limitation related to beam conductivity and reflection.

4. As a solid-state laser, Nd: YAG laser does not produce harmful gases. It is flexible, compact than the gas made lasers, safe, and eco-friendly.

\section{ACKNOWLEDGMENTS}

The authors thank the Forest and Woodworking Machinery Tech. Center of the Northeast Forestry University for the machine facilities under this research and all the work teams. Our gratitude goes to Northeast Forestry University and all members of the College of Mechanical and Electrical Engineering. Special thanks to the reviewers and co-authors for their valuable comments and suggestions.

\section{Research Funding}

This study was supported by the Applied Technology Research and Development Project in Heilongjiang Province of China (No. GA19A402); and Fundamental Research Funds for the Central Universities (No.2572020DR12). 


\section{REFERENCES CITED}

Almeida, J., Liang, D., and Vistas, C. R. (2018). “A doughnut-shaped Nd : YAG solar laser beam," Optics and Laser Technology, Elsevier Ltd, 106, 1-6. DOI: 10.1016/j.optlastec.2018.03.029

Borges, B. M. F. D. C. A. (2008). "Laser cladding using filler powder and wire," Seperior University of Lisbon.

Chien, C. Y., and Gupta, M. C. (2005). "Pulse width effect in ultrafast laser processing of materials," Applied Physics A: Materials Science and Processing, 81(6), 1257-1263. DOI: $10.1007 / \mathrm{s} 00339-004-2989-\mathrm{z}$

Choudhury, I. A., and Shirley, S. (2010). "Laser cutting of polymeric materials: An experimental investigation," Optics \& Laser Technology 42(3), 503-508. DOI: 10.1016/J.OPTLASTEC.2009.09.006

Fork, R. L., Schehrer, K. L., Hirlimann, C., Avramopoulos, H., Fragnito, H. L., and Becker, P. C. (1989). "Amplification of femtosecond optical pulses using a double confocal resonator," Optics Letters, 14(19), 1068-10700. DOI: 10.1364/ol.14.001068

Gautam, G. D., and Pandey, A. K. (2018). "Pulsed Nd:YAG laser beam drilling: A review," Optics and Laser Technology 100, 183-215. DOI: 10.1016/j.optlastec.2017.09.054

Gong, Y. (2014). An on-line learning and training tool for laser cutting, Master's Thesis, University of Manchester, Manchester, United Kingdom.

Guillas, C., Le, C., Theveney, S., and Lefebvre, P. (1990). "Comparative performances of C02 and YAG lasers in the cutting of stainless steel," SPIE 1277, 244-255.

Hernandez-Castaneda, J. C., Kursad Sezer, H., and Li, L. (2011a). "The effect of moisture content in fibre laser cutting of pine wood," Optics and Lasers in Engineering 49(9-10), 1139-1152. DOI: 10.1016/j.optlaseng.2011.05.008

Hernandez-Castaneda, J. C., Sezer, H. K., and Li, L. (2009). "Statistical analysis of ytterbium-doped fibre laser cutting of dry pine wood," Proceedings of the Institution of Mechanical Engineers, Part B: Journal of Engineering Manufacture 223(7), 775789. DOI: 10.1243/09544054JEM1397

Hernandez-Castaneda, J. C., Sezer, H. K., and Li, L. (2011b). "Single and dual gas jet effect in Ytterbium-doped fibre laser cutting of dry pine wood," International Journal of Advanced Manufacturing Technology 56(5-8), 539-552. DOI: 10.1007/s00170011-3209-6

Hernandez, J. C., Crouse, P., and Li, L. (2007). "High-power Yb-doped fibre laser for cutting dry pine wood," in: World Congress on Engineering, London, U.K., 2-7.

Kalokasidis, K., Onder, M., Trakatelli, M. G., Richert, B., and Fritz, K. (2013). "The effect of Q-Switched Nd:YAG $1064 \mathrm{~nm} / 532 \mathrm{~nm}$ laser in the treatment of onychomycosis in vivo," Dermatology Research and Practice, 2013. DOI: 10.1155/2013/379725

Leone, C., Pagano, N., Lopresto, V., and Iorio, I. De. (2009). "Solid state Nd:YAG laser cutting of CFRP sheet: Influence of process parameters on kerf geometry and HAZ," in: The $17^{\text {th }}$ International Conference on Composite Materials, 1-10.

Li, J.-Z. (2016). Microscopic Analysis and Experimental Study of Laser Processing Quality of Wood, Master's Thesis, Northeast Forestry University, Harbin, China.

Maiman, T. . (1960). "Stimulated optical radiation in ruby," Nature Materials, 187(4736), 493-494. DOI: 10.1038/187493a0

Olsen, F. O., and Alting, L. (1995). "Pulsed laser materials processing, ND-YAG versus 
CO2 lasers," CIRP Annals - Manufacturing Technology 44(1), 141-145. DOI:

10.1016/S0007-8506(07)62293-8

Peters, C. C., and Marshall, H. L. (1975). "Cutting wood materials by laser," US For Prod Lab Res Pap, Juneau, Alaska 99801, 12.

Pocorni, J., Han, S. W., Cheon, J., Na, S. J., Kaplan, A. F. H., and Bang, H. S. (2017). "Numerical simulation of laser ablation driven melt waves," Journal of Manufacturing Processes 30, 303-312. DOI: 10.1016/j.jmapro.2017.09.032

Powell, J. (1998). $\mathrm{CO}_{2}$ Laser Cutting, Springer-Verlag London Limited. DOI: 10.1007/978-1-4471-1279-2

Powell, J., and Kaplan, A. (2004). "Laser cutting: From first principles to the state of the art," in: Pacific International Conference on Applications of Lasers and Optics, Laser Institute of America, Melbourne Australia, 1-6. DOI: 10.2351/1.5056075

Schuocker, D. (1989). "Laser cutting," Materials and Manufacturing Processes 4(3), 311-330. DOI: 10.1080/10426918908956297

Senthilkumar, V., Raja, P. P. K., Raj, R. P., Periyasamy, S. R., and Sakthidharan, S. (2016). "Experimental investigation and analysis of process parameters for laser cutting process," International Journal of Innovative Research in Science, Engineering and Technology, 5(8), 151-158.

Shabbusharma. (2020). "ND YAG laser working, construction and definition," $<$ https://physicswave.com/>.

Sharma, A., and Yadava, V. (2013). "Modelling and optimization of cut quality during pulsed Nd:YAG laser cutting of thin Al-alloy sheet for curved profile," Optics and Lasers in Engineering. DOI: 10.1016/j.optlaseng.2012.07.012

Sharma, A., and Yadava, V. (2018). "Experimental analysis of Nd-YAG laser cutting of sheet materials - A review," Optics and Laser Technology 98, 264-280. DOI: 10.1016/j.optlastec.2017.08.002

Svelto, O. (2010). Principles of Lasers, Persepsi Masyarakat Terhadap Perawatan Ortodontik Yang Dilakukan Oleh Pihak Non Profesional, (D. C. Hanna, ed.), Springer London, Milan, Italy. DOI: 10.1007/978-1-4419-1302-9

Tahir, B. A., Ahmed, R., Ashiq, M. G. B., Ahmed, A., and Saeed, M. A. (2012a). "Cutting of nonmetallic materials using Nd:YAG laser beam," Chinese Physics $B$, 21(4), 44201. DOI: 10.1088/1674-1056/21/4/044201

Tahir, B. A., Ahmed, R., Ashiq, M. G. B., Ahmed, A., and Saeed, M. A. (2012b). "Cutting of nonmetallic materials using Nd:YAG laser beam," Chinese Physics B, 21(4). DOI: 10.1088/1674-1056/21/4/044201

Trumpf. (2007). Technical Information Laser Processing: $\mathrm{CO}_{2}$ Laser, SCRIBD.

Wandera, C. (2006). Laser Cutting of Austenitic Stainless Steel with a High Quality Laser Beam, Master's Thesis, Lappeenranta University of Technology, Lappeenranta, Finland.

Xie, X.-Z., Xin, W., and Wei, H. (2008). "Theoretical model of $\mathrm{CO}_{2}$ laser cutting nonmetal material," Tool Engineering 42(5), 19-21. DOI: 10.3969/j.issn.10007008.2008.05.006

Jiang, X., Li, J., Bai, Y., Wu, Z., Yang, C., and Ma, Y. (2016). "Laser Cutting Wood Test and Influencing Factors of Processing Quality," Laser \& Optoelectronics Progress, 53(3), 031403. DOI: 10.3788/lop53.031403

Yang, C., Deng, Z., Li, F., Jiang, X., Guo, C., and Ma, Y. (2018). “Design and experiment for a numerical control nanosecond water-jet-guided laser processing test bench," BioResources 13(2017), 6098-6109. DOI: 10.15376/biores.13.3.6098-6109 
Yang, C., Jiang, T., Yu, Y., Dun, G., Ma, Y., and Liu, J. (2018). "Study on surface quality of wood processed by water-jet assisted nanosecond laser," BioResources, 13(2), 3125-3134. DOI: 10.15376/biores.13.2.3125-3134

Yang, C., Liu, Q., Li, X., Miao, Q., Ma, Y., Doumbia, B., and Ren, C. (2019). "Theoretical process parameter calculation and test verification of laser cutting veneer," Linye Kexue/Scientia Silvae Sinicae, 55(12). DOI: 10.11707/j.10017488.20191218

Yang, C., Lu, Y., Ma, Y., Ren, C., Bai, Y., and Cao, F. (2017). "Theoretical and experimental study on the cutting of wood by nanosecond pulse laser," Linye Kexue/Scientia Silvae Sinicae, 53(9), 151-156. DOI: 10.11707/j.1001-7488.20170918

Zhou, B. H., and Mahdavian, S. M. (2004). "Experimental and theoretical analyses of cutting nonmetallic materials by low power $\mathrm{CO}_{2}$-laser," Journal of Materials Processing Technology 146(2), 188-192. DOI: 10.1016/j.jmatprotec.2003.10.017

Zhu, M., and Hall, J. L. (1997). Atomic, Molecular, and Optical Physics: Electromagnetic Radiation, Experimental Methods in the Physical Sciences.

Article submitted: November 10, 2020; Peer review completed: January 2, 2021;

Revisions accepted: February 1, 2021; Published: February 8, 2021.

DOI: 10.15376/biores.16.2.2416-2432 